International

Medical Society

http://imedicalsociety.org

\section{Access and Accessibility to the Family Health Program in a Small Municipality}

\section{Abstract}

This study aimed to evaluate the population access/accessibility to the Family Health Program (FHP) in a small municipality. This is an impact assessment with quantitative and qualitative approach, developed from a case study in the Municipality of Taipu/RN, Brazil. Data were collected between July 2011 and January 2012 from 72 users of the FHP who responded to a structured questionnaire. Data were analyzed based on the theoretical framework of the program and through descriptive statistics and content analysis. Strict results point that the program coverage has been expanded but this has not been followed by improved access indicators or by the reduction of barriers to accessibility. There has been a substantial increase in available services, but barriers that prevent the user to access the service needs to be the main goal in order to meet health needs.

\section{Introduction}

Historically, one of the major challenges to health systems worldwide has been to offer proper access to populations. In Brazil, the Sanitary Reform Movement and the achievements resulting from this process were starting points for the advancement of discussions and of the incorporation of a new logic when planning healthcare and expanding the access to health services [1].

The Family Health Program (FHP) was created in 1994 with attention and care directed to the individual, the family and the community. The program was elevated to the category of Strategy due to its strong potential as inducer of changes and its importance to the reorganization of the primary care setting and, therefore, as the system gateway [2].
Paula Fernanda Brandão Batista dos Santos ${ }^{1}$, Lincoln Moraes de Souza1, Eliabe Rodrigues de Medeiros ${ }^{1}$, Clélia Albino Simpson ${ }^{1}$

1 Federal University of Rio Grande do Norte. Natal, RN, Brazil.

Contact information:

\section{Paula Fernanda Brandão Batista} dos Santos.

Address: Federal University of Rio Grande do Norte, Health Sciences Center, Department of Nursing. BR 101, s/n, Lagoa Nova, CEP: 59072-970. Natal, RN, Brazil.

” paulafernandabb@hotmail.com

Keywords

Family Health Strategy;

Evaluation of Health Programs and Projects; Access to Health Services. 
Despite the intense progress made possible by the $\mathrm{FHP}$, its expansion in large municipalitites still happens in a limited way, contrary to what was thought in the beginning. Smaller municipalities, in turn, are covered in nearly $100 \%$ of the extent of their populations, while municipalities that have more than 100,000 inhabitants, have between 30\% and 50\% of their populations covered [3].

Since its implementation, much has been discussed about the access, the expansion of coverage of health services and about ensuring the universality of this attention. For this, the Ministry of Health has affirmed social commitment in this process, whose mission is to reorganize the Basic Health Units (BHU) so that they may guarantee the access, become resolutive and establish commitment and accountability links between health professionals and the population in a practice of comprehensive and participatory health [3].

The terms "access" and "accessibility" are used interchangeably and, often, ambiguously. In this paper, the term "access" refers to the entry into health systems [4], the appropriate use of personal health services to achieve the best possible results [5]. Thus, because access is closer to the personal aspect of using the service, it is not enough to show effective results in health care expansion policies.

Accessibility here relates to a feature of the health system, the condition guarantee of universal access to all. Thus, it must be seen as additional to the presence or to the availability of a resource and must enclose the characteristics that facilitate or hinder the use by users [4]. It is related to the possibility of people come to the services, which directly reflects an aspect of the structure of a system or health unit that essential to characterize the services as gateway. Accessibility is used as a central category to assess the universalization, with regard to the expansion of care to the entire population, and the establishment of a gateway to the health system caused by the program [6].
From these considerations, it is worth noting the peculiarity of dealing with this issue in the FHP in small municipalities of the Northeast, since they are mainly made up of rural areas with socioeconomic characteristics that most likely hinder people's access to health services [7]. This is different from what happens in urban areas, which often have various health services such as primary care teams, specialized services and greater access to other levels of the system.

One way to approach this issue is through evaluative studies, such as impact assessments. These work the results of an intervention according to its levels of achievements such as: strict results, effects and impacts [8]. Strict results of the program refer to the direct product of services offered by the FHP to the targeted population. The effects, in turn, refer to the results that are derived from the products (strict results) and that have a causal relationship with the FHP. These are changes that affect the population and the health care team, but are limited to the scope of the Program and its beneficiaries, and may be short-lived. The impacts are the groups of effects that go beyond the limits of the program and ofthe beneficiary community [9], causing permanent or significant changes in the lives of people [10].

Considering these characteristics, the following question was raised: To what extent the access/accessibility of populations of small municipalities to the FHP in Rio Grande do Norte has been effected? To answer this question, evaluating the access/accessibility of the population of a small municipalitiy in RN, Brazil, to the FHP was established as objective of this study.

\section{Method}

This is a study of impact assessment with quantitative and qualitative approaches and developed based on a case study, through a non-experimental design. This article is a part a doctoral thesis called 
"the Family Health Program Evaluation in Rio Grande do Norte" [11], as arguments and later additions are also part of this thesis.

The choice of the municipality was based on the following selection criteria: degree of coverage and year of implementation of the FHP. Taipu was chosen because it is a small municipality (has a total population of less than 20,000 inhabitants) and one of the first municipalities to implement the program in the state, with a coverage of $100 \%$ of the population at the time of this survey.

It is located in the State of Rio Grande do Norte, $52 \mathrm{~km}$ from the capital. It has a land area of $352.82 \mathrm{~km}^{2}, 11,836$ inhabitants, 7,752 residents in rural areas and 4,084 in urban areas, Human Development Index of 0.583 and 16 health care facilities distributed in 15 public and one private [12].

The FHP in the municipality has five family health teams, three in rural areas and two in urban areas. The teams that cover the urban area share the same health unit, along with the head office of the County Health Department and specialized services such as Physiotherapy, Speech therapy and Medium Complexity tests (endoscopy, ECG, etc.).

Teams of rural areas have no fixed central office; their activities are carried out in schools and health posts located in different areas. These teams cover six to seven rural areas, 4 to $10 \mathrm{~km}$ far from each other. The number of families assisted per team is 576.6 in average, with lowest and highest number of families assisted per team corresponding to 470 and 757 , respectively.

The criteria for delimitation of the sample was the theoretical sampling, which is a gradual strategy of building from the process of collecting and interpreting data. The delimitation of total number of interviews was based on a pilot study and on a number approaching the theoretical saturation of data [13].

Subjects were randomly selected from records available in BHUs. A total of 100 medical records were drawn up, delimiting 20 questionnaires per team. Thus, family members who were present in their homes during home visits were the participants of the study.

Inclusion criteria were: person who is beneficiary of the program, a member of the randomly chosen family, 18 years old and who voluntarily accepted to participate in the study.

Data collection took place between July 2011 and January 2012 through a structured questionnaire that contained open and closed questions. Interviews were recorded, allowing access to important information when they were performed.

Speeches as identified by the term "questionnaire", represented by the letter Q, followed by the number of the municipality, whereTaipu was represented by the number 06, and followed the number corresponding to each of the respondents.

Analysis and interpretation of data were based on the theoretical framework of the program and corresponding literature. Quantitative data were organized in tables and analyzed in the light of the descriptive statistics. For the analysis of qualitative data, the steps of content analysis were used aiming to summarize the information obtained through key categories. The steps used were: strict reading of the speeches, grouping in categories based on the keywords of each speech, and analysis and interpretation of the main highlighted categories [14].

In order to evaluate the principle of universality, in the subdimension access/accessibility, the analysis in the levels of strict results and effects will be placed according to the matrix of indicators shown in Table 1. As for the criteria used to measure these results, effectiveness and effectivity were taken into account [15].

Because this was a research involving human beings, this study complied with the requirements of Resolution 466/2012 of the National Health Council [16], and the subjects of the research were requested to sign the Informed Consent. The study was submitted to the Ethics Committee of the Fede- 
Table 1. Matrix of indicators/criteria for evaluation of the FHP.

\begin{tabular}{|c|c|c|c|c|}
\hline $\begin{array}{c}\text { Level of } \\
\text { Measurement }\end{array}$ & $\begin{array}{l}\text { Level of } \\
\text { realization }\end{array}$ & $\begin{array}{l}\text { Indicator } \\
\text { /Criteria }\end{array}$ & Unit of analysis & $\begin{array}{l}\text { Means of } \\
\text { Verification }\end{array}$ \\
\hline Efficacy & Strict results & Coverage degree of the FHP & Municipality & SIAB \\
\hline Efficacy & Strict results & $\begin{array}{l}\text { Annual average of medical and nursing } \\
\text { consultations per inhabitant }\end{array}$ & Municipality and BHU & SIAB and IBGE \\
\hline Efficacy & Strict results & $\begin{array}{l}\text { Annual average of home visits by Community } \\
\text { Health Agents (CHA) }\end{array}$ & Municipality and BHU & SIAB \\
\hline Effectiveness & Effects & $\begin{array}{l}\text { User perception regarding: access barriers to basic } \\
\text { consultations and examinations (geographic, } \\
\text { organizational, cultural and financial) }\end{array}$ & Municipality and BHU & Questionnaire \\
\hline
\end{tabular}

Source: Self elaboration, 2016

ral University of Rio Grande do Norte and approved under Opinion $n^{\circ} 371 / 2011$ and number of CAAE 0189.0.051.000-11.

\section{Results and Discussion}

The study included 72 users of the FHP, which were mostly females (94.44\%), with a prevalence of ages between 36 and 45 years (22\%) followed by ages between 26 and 35 years (21\%). About half of these people have education level corresponding to incomplete primary education (56\%), married (56\%) followed by single (25\%) and people living in common-law marriage (11\%) and most of them (62\%) receive help from the federal government and has income between one (44\%) and two minimum wages $(21 \%)$ and live in their own house (89\%).

In these households, there are subjects younger than 14 years old (54\%) adults between 15 and 59 years old (94\%) and elderly over 60 years old (31\%) and as regards the residence time, many have lived in that neighborhood (89\%) for over 10 years and use the FHP since its implementation. Thus, they attend the FHP in monthly basis (45\%), but there are people who rarely go the the program (38\%).

Families that are included in priority groups assisted by the program particpated in the present study, namely, people with hypertension (40.27\%), children under 2 years (12.5\%) and pregnant women
(4.16\%). This fact reinforces that the main services demanded by users are consultations (97.22\%), search for medicines (73.61\%) and vaccination (36.11\%), with the exception of a few (12.5\%) who said to attend the FHP to share in educational works.

Thus, the profile of the participants points to a population of young adults, with their own house, but with little schooling and low income in general, beneficiaries of welfare policies and income from the federal government.

These factors, associated with the characteristics of the use of the service, will demonstrate the importance of the FHP for this population. This is because this may represent not only the service that is mostly sought by these individuals, but also the only one. This is the case of the population living in rural areas. When compared to urban areas, these have increased demand for primary care services, in this case, the FHP. This reality is evidenced by the difficulty in accessing other services, particularly due to socioeconomic and geographical barriers, such as the absence of public transportation to take these people from these areas to the city center and also the large distances to be covered. Furthermore, there are financial barriers, such as the lack of money or resources to do these trips.

The strict results of the program are related to inputs, the initial products and intermediate objectives of the program and do not show changes in 
the target audience or the social situation of the beneficiaries. They are generally limited to records and descriptions in terms of measuring the actions taken [9]. In the FHP, the degree of coverage in the municipalities, the annual average of medical consultations per inhabitant in basic specialties and the monthly average of home visits per family by $\mathrm{CHA}$ were selected as strict results.

These indicators may provide an overview of the evolution of significant actions to the FHP such as increasing the offer of services such as medical consultations, representing the increasing access to primary care, increased monitoring of families relating to home visits carried out by CHA. However, considering the values of these indicators does not inform, by itself, the quality, meanings and other elements of the services offered.

Regarding access to the FHP, it was observed that the municipality of Taipu began to implement the FHP in 1998 with a team that would cover 3,450 people, equivalent to $33.57 \%$ of the local population. In 2004, the level of coverage $100 \%$ of the population with four teams was achieved, increasing to five teams to cover the entire population in the following year, as outlined in Table 2.

Table 2. Historical series of implementation of FHP, Taipu/RN, Brazil, 1998-2010.

\begin{tabular}{|l|c|c|c|}
\hline \multicolumn{1}{|c|}{ Period } & $\begin{array}{c}\text { Teams } \\
\text { Deployed }\end{array}$ & $\begin{array}{c}\text { Population } \\
\text { Covered }\end{array}$ & $\begin{array}{c}\text { Proportion of } \\
\text { Population } \\
\text { Coverage (\%) }\end{array}$ \\
\hline $1998-2000$ & 1 & 3,450 & 33.57 \\
\hline $2001-2003$ & 3 & 10,350 & 88.84 \\
\hline 2004 & 4 & 12,568 & 100.00 \\
\hline $2005-2010$ & 5 & 12,568 & 100.00 \\
\hline
\end{tabular}

Source: Primary Care Information System, 2012.
As for the results achieved by the teams, service indicators are important to see if they can guarantee the minimum recommended by the Ministry of Health. In this sense, two of them were selected, namely: annual average of medical consultations per inhabitant, and monthly average of home visits per family per community health agent. These were chosen because they are frequently used by the Ministry of Health and because they have goals well established.

By analyzing this data, it was found that the municipality initially had favorable data but has had declining results in recent years, not reaching the minimum required, even with FHP coverage of $100 \%$ of the municipality, as outlined in Table 3.

According to the Pact of Indicators of Primary Care realized in 2006, the goal was to launch one consultation per inhabitant per year and one monthly home visit by $\mathrm{CHA}$ per inhabitant [17]. It was observed that, in Taipu, there was a considerable decrease of these values, changing from satisfactory or almost satisfactory in 2001 to very unsatisfactory in 2006. This information was not present in a few years (2004, 2005 and 2006, in the case of home visits).

These values were decreasing, not following the expansion of the program in the same period. Thus, there was a decrease in health care provision in basic specialties at the same time that the network of health posts with FHP was being expanded to a coverage of $100 \%$ of the population at the end of 2006.

Increase of the number of families assisted per team was not observed either. Thus, by the end of 2006, the municipality did not reach the minimum coverage recommended by the Ministry of

Table 3. Historical series of general indicators of Primary Care. Taipu/RN, Brazil, 2001-2006.

\begin{tabular}{|l|c|c|c|c|c|c|}
\hline \multicolumn{1}{|c|}{ Indicators } & $\mathbf{2 0 0 1}$ & $\mathbf{2 0 0 2}$ & $\mathbf{2 0 0 3}$ & $\mathbf{2 0 0 4}$ & $\mathbf{2 0 0 5}$ & $\mathbf{2 0 0 6}$ \\
\hline Annual average of medical consultations per inhabitant in basic specialties & 1.18 & 1.71 & 0.78 & - & - & 0.10 \\
\hline Monthly average of home visits by CHA to families & 0.98 & 0.78 & 0.42 & - & - & - \\
\hline
\end{tabular}

Source: Primary Care Information System, 2012. 
Health with regard to medical consultations in basic specialties, even with a number of families within the standards established by the Ministry of Health, which is between 600 and 1000 families by assisted by each team and with $100 \%$ of coverage.

This lack of coherence between indicators and coverage is possibly related to the expansion of the program in rural areas, given that the first teams were concentrated in the urban area, where the population has easier access to health services. On the other hand, this can also be linked to flexibility in the time of medical professionals to give assistance in these locations. To address the difficulty of attracting these professionals to stay in the program, various adjustments in working conditions have been introduced, and one of them is the non-compliance with the workload of 40 hours per week.

Explanations may be many, but it is possible to infer: a substantial increase in teams came with the expansion of the program, leading to $100 \%$ coverage of the municipality. However, this expansion did not represent a significant increase in the offer of health care or home visits by CHA in the proportion envisaged by the FHP.

This may be relevant when other situations involving accessibility conditions are analyzed. Despite the availability of the service, this often does not match the minimum expected and necessary to the population.

However, one must consider that the increase in the number of teams and full coverage of the FHP alone do not represent the only elements capable of ensuring access. Concomitantly, conditions of accessibility need to be considered, since this is what will determine whether the service being offered can meet the needs of the population and ensure the use, and in that sense, the effects of the program.

With regard to these, one can consider them the result of the use of products of the program, which are directly related to the effectiveness of results brought to the beneficiary population. [9] Therefo- re, accessibility is evaluated based on the reference to the FHP as the system gateway, in addition to accessibility barriers that reflect the difficulties that users face to access the services of the program.

It was observed that, in the municipality of Taipu, in a acse of urgency and/or emergency, the first service referred to care is the hospital (95\%) and in the case of a new problem that iis not an urgency and/ or emergency, most people seek the BHU (93\%). This fact leads to high search for health posts as the first place of assistance, that is, as a gateway to the municipal health system.

Given this reality, the FHP can be understood as the gateway to the health service in the municipality of Taipu. However, we must also consider that this municipality has a limited supply of services, mainly because of its population living mostly in rural areas, and because the FHP is the only the existing health service.

This phenomenon brought by the program in the municipality, for being implemented mainly in areas previously devoid of other public health facilities, has guaranteed an increase in the demand and has caused it to become the gateway to the system, which is an expected and positive effect.

The parameters for evaluation of the barriers to accessibility were: waiting time for receiving the assistance (result of the time interval between arrival and the moment of realization of the consultation), difficulty for scheduling consultations and scheduling exams. These indicators were selected because they were the more expressive when users reveal the reasons that led them to seek health services. Consultations are the main services sought in health facilities and may represent barriers encountered in their use.

Difficulties in scheduling consultations in the FHP were pointed by $63 \%$ of participants. The groups considered as priority (hypertension, diabetes, pregnant women, children under 1 year of age, among others) have no difficulty in scheduling consultations for the specific day for the care of these groups. 
However, when there is need for a consultation on another day, the difficulty is the same of the faced by the population that is not defined in these groups.

With regard to the scheduling laboratory tests, only $21 \%$ of respondents had faced difficulties in this process. In general, they were users living in the rural area, and this difficulty is due to the need to travel to the urban area to perform the procedure, receive the result, among other activities, generating costs often unexpected and inconsistent with the financial conditions of these families.

For families, the main problem to access the program through consultation is the distribution of tickets in the organization of this activity and short time of medical care in the FHP for a considerable demand of people. Each team has a fixed and previously defined number of medical queries per day, which are from 12 to 30 queries per shift organized through distribution of tickets.

Unlike the urban area, the rural area has a feature that has generated an even greater difficulty relating to consultations and medical care. The team assistance to the community is mostly carried out only weekly or fortnightly. Thus, the difficulties are magnified because the provision of the service is limited to these communities. Here is an example of the speech of users:

Because you have to wake up very early, and the dentist is even worse, because there are few tickets. I prefer to save money and pay for a private consultation, because you have to sleep in line to get a ticket. And sometimes you leave home at 4 hours in the morning and you still don't get it. When you arrive, everything is already full. I very often go there (to the hospital), then, when they send me go down, I go and take the medicine on my own. I know I'm causing myself trouble, but it's really hard to get a ticket.

Q.06.68
The difficulty is because the time he spends here is very short, he comes every 8 days, and only receives 12 people. I guess this is wrong, if he only comes from 8 to 8 days, he should stay at least all day long.

Q.06.04.

Considering these facts, problems and difficulties appear, so that when people need care, they have to wait for the doctor of the FHP to return the community. If they seek the hospital, they will face difficulty in receiving assistance; the guidance given in this service is that, because it is not a case of urgency/emergency, the user should seek the FHP in his home community to receive care. Thus, the population ends up without the service of the FHP, due to the restriction imposed by the days of care, and without access to the hospital because this understands that this is a demand for the FHP.

Consequently, this forces the user in all situations to seek, first, assistance at BHU, and only after this, seek the hospital care. Most of them prefer to seek hospital care because when they succeed in receiving the assistance, they can receive it at any time, and without the restriction of tickets that is present in the FHP service. The barriers are smaller and this turns the service more attractive.

Another restriction has to do with the number of tickets distributed to medical care. In an attempt to prevent "illegal trade of tickets" - characterized by a group of people that during the night go to the line to get tickets and in the morning sells them to those who need care - only one ticket per family is distributed, giving the right to only one user receive assistance.

Professionals understand that by doing so, they could reduce this "illegal trade". However, the population says that this situation has generated more difficulty to getting access to the query in the program. According to participants, when two people in the family are sick, only one receives medical care, because only one member of the family can receive a ticket. 
It's hard, because sometimes... For an example, you have two sick people in a home, in a family. They do not receive the consultation, only one receives, you cannot get two tickets in the same house. Now, how will the person know which day he will get sick? When we are sick, sick the whole week, then you have to wait to see the doctor only on Monday. There (in Taipu - hospital) they give assistance, but they have that saying...

Q.06.19.

When the doctor is not here we go Taipu, but there they are complaining all the time, too, because I've been there and I know. "And you go to the post there, look for the people there." So, in this case, if you do not have it here, of course you have to go there... There in the hospital, they do not want to give us assistance, it happened to me once.

Q.06.28.

In relation to the waiting time for the service, it was not possible o define it, since, in order to receive assistance, people show up during the night in search of a ticket for medical or dental care. Some say they wait in the queue since the night of the previous day, others since three in the morning, and so on.

After delivery of the tickets, which usually occurs between seven and seven thirty in the morning, users return to their homes to make their meals, returning then to be assisted. Since, most of the times, they do not know when the professionals arrive, there is no way to measure the time it takes to receive assistance.

Even with the inability to make a fair assessment of the waiting time, it is identifiable that this has been a major problem reported by users with regard to receiving assistance in the program.

The FHP, as the health system gateway, is an outstanding achievement from the point of view of system organization, reduction of costs with high technology, rationalization of expenses with health, appropriate targeting of health problems according to user needs. However, while the program becomes the gateway, in many municipalities this is a "narrow gateway" with adverse effects on the portion of population that is the more needy of services, like the rural population in small towns [18].

When service is limited to the FHP and the necessary conditions to meet the demand are not offered, there is a restriction of the right and not an extension of access. This scenario points to a possible setback, since going to BHU to try the first service has become an imposition of other referenced services.

In such cases, the user ends up sojourning for health services to try to solve his problem. So, the program would be a positive strategy used today by hospitals if the FHP gave the necessary coverage to these populations.

The imposed restriction of access to rural areas is also noticeable in other studies [19]. Long distances and small populations, in addition to the barriers to accessibility imposed to the teams and to users, the lack of infrastructure for the service, are also elements that reveal distortions and difficulties to expand the access of health care for this population.

In general, for populations of urban and rural areas, the distribution of tickets represents the main organizational barrier mentioned by users regarding scheduling consultations, especially medical queries, in the FHP. In other research has also been observed that the tickets and the queues are the main problems identified by the population and that this situation was partly attributed to the small number of doctors in BHU as well as the lack of experts [20].

It is important to consider that when it comes to ensuring the universalization of the service, access has a fundamental character, because inequalities in the use of services also reflect inequalities in the process of becoming ill and dying. In these terms, 
the equity desired by the program is compromissed when populations that are considered the most vulnerable receive limited care.

Thus, the conditions of accessibility, defined as the degree of coherence between the characteristics of health resources and the characteristics of the population in the process of seeking and obtaining health care, reveal the gap that the program still has when it comes to ensure the minimum necessary to populations, particularly to the rural population, with regard to universal health care. [21].

No results were found with regard to the impact of the program, which could express, for example, the effective changecaused by the program on the lives of these people. The results point data that allow the verification of strict results and effects of the program, but there is not yet enough information to identify impacts in this regard.

\section{Conclusion}

Access to primary health care through the FHP in Taipu, when considered only in terms of increased offer of program teams, has skyrocketed in recent years, but when general indicators of access and barriers to accessibility were associated with this increase, it was observed that this has not been accompanied by improvements and guarantee of attention to the beneficiary population.

The expected positive effects achieved in the program can be summarized as follows: the program is considered the system gateway to situations that are not cases of urgency/emergency; there is the guaranteed attention/monitoring to priority groups. Negative effects included: difficulties in accessing services in rural areas and limited care per family (tickets).

Although the FHP represents the gateway to the health system, there are still many barriers to accessibility, to ensuring access, so that this may represent the expansion and improvement of the offer of primary care that the local population needs.
The highlighted barriers are mainly in areas that are already historically poor in terms of services, such as rural communities. In addition to the difficulties that the environment itself brings, there is a limitation in the days of service teams, in the offer of services, since not all are offered in rural areas, as for example dental care, cervical prevention exams, among others. This makes these communities to need to move in order to be assisted elsewhere. Other issue is the shift on which the service is provided (morning shift), which is not always compatible with the work in the field.

As regards the program as a gateway, a limiting situation of access reflected in the choice of primary care was demonstrated, and this is also more critical for users living in rural areas. If, on the one hand, the adscription of the clientele allows better monitoring of the population in relation to their health/disease process, on the other hand, the limiting conditions of care imposed on users generate difficulties to get the necessary medical care.

In view of these considerations, it can be inferred that the FHP passed through a substantial increase in the offer of services, but we still need to minimize barriers that prevent users to get to the service and to use it properly to meet their health needs. Thus, in spite of some progress, one cannot say, properly, that there have been impacts, because they did not occur in the fundamental, profound and constant changes in people's lives.

\section{References}

1. Paiva CHA, Teixeira LA. Reforma sanitária e a criação do Sistema Único de Saúde: notas sobre contextos e autores. Hist ciênc saúde-Manguinhos. 2014;21(1):15-25.

2. Silva LA, Casotti CA, Chaves SCL. A produção científica brasileira sobre a Estratégia Saúde da Família e a mudança no modelo de atenção. Ciênc saúde coletiva. 2013;18(1):221-232.

3. Santos PFBB. O Enfermeiro na implantação e desenvolvimento do programa saúde da família em Campina Grande: a luz da história oral temática [dissertação]. João Pessoa (PB): Universidade Federal da Paraíba; 2004 
4. Lora AP. Acessibilidade aos serviços de saúde: estudo sobre o tema no enfoque da saúde da família no Município de Pedreira, São Paulo [dissertação]. Campinas (SP): Universidade Estadual de Campinas; 2004.

5. Millman M. Access to health care in America. Washington: National Academy Press; 1993.

6. Starfield B. Atenção primária: equilíbrio entre necessidades de saúde, serviços e tecnologia. Brasília: UNESCO, Ministério da Saúde; 2004.

7. Unglert CVS, Rosenburg CP, Junqueira $C B$. Acesso aos serviços de saúde: uma abordagem de geografia em saúde pública. Rev saúde pública. 1987;21(5):439-46.

8. Draibe SM. Avaliação de implementação: esboço de uma metodologia de trabalho em políticas públicas. In: Barreira MCRN, Carvalho MCB. Tendências e perspectivas na avaliação de políticas e programas sociais. São Paulo: IEE/PUC-SP; 2001. p. 13-41.

9. Souza LM. Três ensaios sobre avaliação de políticas públicas. Natal: EDUFRN; 2014.

10. Roche C. Avaliação de impacto dos trabalhos de ONGs: aprendendo a valorizar as mudanças. 2 ed. São Paulo: Cortez; 2002.

11. Santos PFBB. Avaliação do Programa Saúde da Família no Rio Grande do Norte [tese]. Natal (RN): Universidade Federal do Rio Grande do Norte; 2013

12. Instituto Brasileiro de Geografia e Estatística (BR). Cidades [internet]. 2016 [citado em 2016 fev 29]. Disponível em: http:// cod.ibge.gov.br/j7z

13. Flick U. Introdução à pesquisa qualitativa. 3 ed. Porto Alegre: Artmed; 2009.

14. Minayo MCS. O desafio do conhecimento: pesquisa qualitativa em saúde. São Paulo: Editora Hucitec; 2014.

15. Figueiredo MF, Figueiredo AMC. Avaliação política e avaliação de políticas: um quadro de referência teórica. A\&C. 1986;1(3):10727.

16. Conselho Nacional de Saúde (BR). Resolução n. 466 de 12 de dezembro de 2012. Trata das diretrizes e normas regulamentadoras da pesquisa envolvendo seres humanos. Brasília: Diário Oficial da União 2013; 13 jun. Seção 1. p. 59-62.

17. Ministério da Saúde (BR). Secretaria de Atenção à Saúde. Departamento de Atenção Básica. Análise dos Indicadores da Política Nacional de Atenção Básica no Brasil. Brasília: Ministério da Saúde; 2008.
18. Azevedo ALM. Acesso à atenção à saúde no SUS: o PSF como (estreita) porta de entrada [dissertação]. Recife (PE). Fundação Oswaldo Cruz; 2007

19. Ribeiro JM, Siqueira SAV, Pinto LFS. Avaliação da atenção à saúde da criança (0-5 anos) no PSF de Teresópolis (RJ) segundo a percepção dos usuários. Ciênc saúde coletiva. 2010;15(2):51727.

20. Sousa MF. O Programa Saúde da Família no Brasil: análise do acesso à atenção básica. Rev bras enferm. 2008;61(2):153-8.

21. Oliveira LR. Avaliação do acesso à saúde aos níveis de atenção de maior complexidade no Município de Marília/SP, sob a ótica da integralidade [dissertação]. Botucatu (SP). Universidade Estadual Paulista; 2010
Publish in International Archives of Medicine

International Archives of Medicine is an open access journal publishing articles encompassing all aspects of medical science and clinical practice. IAM is considered a megajournal with independent sections on all areas of medicine. IAM is a really international journal with authors and board members from all around the world. The journal is widely indexed and classified Q1 in category Medicine. 